\title{
Idosos institucionalizados: uma reflexão para o cuidado de longo prazo
}

Recebido em: 12/8/2011

Aceito em: 15/2/2012
Marylane Viana da Silva ${ }^{1}$

Maria do Livramento Fortes Figueiredo²

O envelhecimento humano é uma condição que vem ampliando progressivamente seu espaço na sociedade, evidenciado pelo processo de transição demográfica e epidemiológica que marcou as últimas duas décadas. Essa reflexão teórica propõe discutir sobre a autonomia do idoso institucionalizado e as possibilidades de cuidados de enfermagem, utilizando conceitos de dependência e autonomia descritos por Agich. Extraíram-se os seguintes aspectos: o cenário do envelhecimento frágil, a incapacidade funcional, o envelhecimento institucional e um novo paradigma de atendimento proposto. A avaliação da capacidade funcional em idosos institucionalizados é necessária para a implementação de ações terapêuticas e no cuidado de longo prazo.

Descritores: Idoso, Institucionalização, Autonomia, Cuidado, Enfermagem.

\section{Institutionalized elderly: a reflection for long-term care}

Human aging is a condition that has gradually expanded its space in society, as evidenced by the process of demographic and epidemiological transition that marked the last two decades. This reflection aims to discuss theoretical autonomy of institutionalized elderly and possibilities for nursing care, using concepts of dependency and autonomy described by Agich. They drew the following aspects: the setting of fragile aging, functional disability, aging and a new institutional service proposed paradigm. The functional capacity evaluation in institutionalized elderly is necessary for the implementation of therapeutic actions and long-term care.

Descriptors: Elderly, Institutionalization, Autonomy, Care, Nursing.

\section{Ancianos institucionalizados: una reflexión para cuidados de larga duración}

El envejecimiento humano es una condición que se ampliado gradualmente su espacio en la sociedad, como demuestra el proceso de transición demográfica y epidemiológica que marcaron las últimas dos décadas. Esta reflexión tiene como objetivo discutir autonomía teórica de ancianos institucionalizados y posibilidades de atención de enfermería, utilizando conceptos de dependencia y la autonomía descrita por Agich. Señalaron a los siguientes aspectos: el escenario del envejecimiento frágil, discapacidad funcional, envejecimiento y un nuevo paradigma de servicios institucionales propuestos. La evaluación de capacidad funcional en los ancianos institucionalizados necesario para ejecución de las acciones terapéuticas y de cuidados a largo plazo.

Descriptores: Ancianos, La Institucionalización, La Autonomía, El Cuidado, Enfermería.

\section{INTRODUÇÃO}

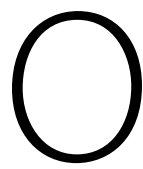
envelhecimento humano é uma tendência do comportamento demográfico no mundo inteiro iniciada nos países desenvolvidos, após o crescimento econômico e industrial que vem influenciando as transformações epidemiológicas populacionais.

O processo de senectude ocorreu de forma gradual nesses países, de modo que o acúmulo de riquezas internas ocorreu antes mesmo da massificação do envelhecimento populacional, não tendo comprometido severamente o acúmulo das riquezas. Já nos países em desenvolvimento, tais transformações têm ocorrido de forma concomitante e até precoce, provocando problemas nos ordenamentos sociais, econômicos e políticos que repercutem diretamente na produção das riquezas internas de um país e nos padrões de desenvolvimento econômico ${ }^{(1)}$.

Em estudos anteriores, observam-se diversas preocupações com o aumento das taxas de envelhecimento e o progresso econômico dos países em desenvolvimento, pois o processo de urbanização, as relações de gênero e trabalho e as transformações econômicas têm provocado novos ordenamentos nas relações familiares que favorecem o isolamento social do idoso, a perda da autonomia e o aumento da incapacidade funcional, que em geral se potencializam com o aparecimento e as complicações das $\mathrm{DCNTs}^{(2-3)}$. A partir desse contexto, este ensaio propõe uma reflexão teórico-conceitual sobre a autonomia do idoso institucionalizado e as possibilidades de cuidados de enfermagem.

\section{METODOLOGIA}

Foi utilizada a metodologia de reflexão teórico-conceitual, a partir das ideias de dependência e autonomia descritas por Agich $^{(4)}$, na perspectiva da bioética do cuidado de longo prazo, inter-relacionando com o fundamento básico da teoria do déficit do autocuidado.

\section{O cenário do envelhecimento frágil}

No Brasil, atualmente, somam-se 15 milhões de pessoas com 60 anos e mais, e para 2025, é esperado que esse número alcance 34 milhões de idosos na faixa etária acima de 80 anos. Há registros indicando que a institucionalização chegue a $0,8 \%$ da população idosa e está associada a problemas de ordem familiar, representando um dos principais fatores que contribuem para o 
aumento das fragilidades e das incapacidades físicas e funcionais nesse grupo etário(2,5).

Nesse aspecto, as implicações do envelhecimento patológico podem produzir sérios problemas para os sistemas sociais de produção de riquezas, benefícios previdenciários e custos com a saúde pública, tanto de ordem preventiva quanto hospitalar, comprometendo, assim, o crescimento econômico dos continentes emergentes.

Esses fatores também são determinados pelos ordenamentos sociais da vida moderna, marcados pela feminização do trabalho formal, que estimulou a saída das mulheres do domicílio e o cuidado com as gerações mais frágeis (crianças e idosos). A diminuição no tamanho das famílias, com a redução das taxas de fecundidade e a migração dos jovens para os centros urbanos, favorecendo a indisponibilidade de cuidadores domiciliares, também contribui para as necessidades de institucionalização ${ }^{(6)}$.

Idosos frágeis podem ter ou não mais idade. Entretanto, o maior grau de dependência física, o uso de medicamentos contínuos, os custos coma assistência àqueles mais dependentes e o fato de serem portadores de comorbidades decorrentes do processo de envelhecimento tornam esses idosos mais frágeis e com pior qualidade de vida.

A síndrome da fragilidade é de origem multifatorial e, portanto, provoca alterações multidimensionais nas pessoas idosas ${ }^{(3)}$, podendo contribuir para o aumento do processo de institucionalização. Isso ocorre sobretudo porque os cuidadores, em geral, são as mulheres (filhas, esposas, netas, sobrinhas). Ao mesmo tempo que precisam manter os cuidados diários contínuos, devem trabalhar fora de casa para manter o sustento familiar e, às vezes, complementar as despesas com a assistência do idoso no domicílio, nem sempre suficiente para suas demandas.

\section{A incapacidade funcional $\mathrm{e} o$ envelhecimento institucional}

A relação da incapacidade funcional acompanha o empobrecimento, pois as despesas médicas, os medicamentos e outras demandas econômicas necessárias à manutenção do idoso são altas, gerando, assim, instabilidade econômica, psicológica e social ${ }^{(6)}$. Tais situações contribuem consideravelmente para o processo de institucionalização.

Estudos nacionais acenam que $0,8 \%$ da população idosa brasileira está convivendo em instituições de longa permanência para idosos (ILPI). Observa-se que a institucionalização não é uma prática comum no Brasil( $^{(2)}$. Mesmo que esses indicadores não revelem grande visibilidade do problema para o cenário nacional, vale considerar que o processo de fragilidade senil e a institucionalização estão em ascensão; portanto, há uma tendência de crescimento em um futuro próximo.

Contudo, nãoé próprio da cultura brasileira institucionalizar seus idosos. O processo de institucionalização tem significados pouco receptivos. Quase sempre é incompreendido e de difícil aceitação tanto para os idosos quanto para aqueles que ousam investigar os motivos que levam as famílias a institucionalizá-los. Além disso, as instituições de longa permanência para idosos (ILPI) eram, outrora, conhecidas como asilos - locais de isolamento, segregação social e geracional, minimamente acolhedoras para seres humanos.

Entretanto, o cuidado nessas instituições está envolto na tomada de decisão em poder e/ou precisar de cuidados de longo prazo frequentes. Mas essa atitude autônoma nãoé tomada pelo idoso. Suas possibilidades de escolha são limitadas, e às vezes, inexistentes, pois a incapacidade vivida por ele diminui o sentimento de autoconfiança e liberdade individual, tornando-o dependente para a realização das atividades cotidianas de sustentação do próprio corpo.

As ILPIs são locais desprovidos de liberdade para seus residentes ${ }^{(6)}$, desde a admissão até sua permanência como "moradores", especialmente porque as normas institucionais, os contratos de permanência no estabelecimento, os riscos de acidentes físicos, a qualidade da assistência e de recursos humanos qualificados para o cuidado ao idoso frágil influenciam na qualidade de vida dessas pessoas.

Essa característica das ILPIs proporciona pelo menos duas interpretações sobre a realidade dos idosos institucionalizados: a primeira, compreendida como sendo aquela obediente ao direito jurídico de funcionamento, que considera sua existência necessária para resolver os problemas de ordem individual, familiar e social, sob a ótica dos regulamentos estatizados. Assim, os cuidados aos idosos com dependência física, mental ou financeira passam a serem assumidos pelas ILPIs, ocultando, à primeira vista, o problema da esfera pública. A segunda trata do significado da autonomia, que culturalmente se traduz em possibilidade de ação com liberdade e independência, condição que não se observa nos idosos frágeis e vulneráveis. A concepção desse valor humano concebido culturalmente é marginalizadora, segregadora e utilitarista, pois contribui para a adoção de informações e conceitos pessoais e sociais pejorativos sobre o envelhecimento, que repercutem nos padrões de beleza, na aversão às idades mais avançadas e na incompletude de ser humano.

\section{Um novo paradigma de atendimento proposto}

A visão do atendimento às necessidades humanas por ações de saúde não se apresenta suficiente para abarcar a complexidade do envelhecimento. Sob esse ponto de vista, observa-se que as possibilidades de interagir positivamente para a melhoria ou a manutenção da saúde dessa população são limitadas aos problemas de saúde, o que torna invisíveis ou distorcidas as diversas questões sociais, políticas, econômicas, familiares e culturais que envolvem o processo de envelhecimento populacional brasileiro.

Por isso, na perspectiva de propor aos governos estratégias de inclusão, participação e maior assistência à população idosa, a Organização Mundial de Saúde (OMS) criou a política de saúde para um envelhecimento ativo, que visa essencialmente a considerar os direitos, as preferências e as habilidades das pessoas mais velhas e não apenas suas necessidades ${ }^{(1)}$. 
Entre a população idosa institucionalizada, é esperado que o envelhecimento ativo seja uma meta e/ou uma consequência da qualidade da assistência multidimensional prestada, pois as variações do grau de independência funcional são diferentes daqueles idosos que vivem no domicílio, sob o amparo e a interação familiar saudável - ou ainda daqueles que descobriram a convivência com seus pares em centros de convivência para pessoas idosas e cujas práticas assistências contemplam atividades físicas, lúdicas, artísticas e de prevenção às doenças.

Em 2006, o Ministério da Saúde do Brasil (MS), através da Política Nacional de Saúde da Pessoa Idosa (PNSPI), definiu o termo capacidade funcional como a qualidade que as pessoas idosas têm para desempenhar as atividades do cotidiano de forma autônoma, independente e $\operatorname{correta}^{(7)}$. Desse modo, o entendimento das incapacidades funcionais estaria associado à interação de fatores ambientais e pessoais e do contexto cultural que interagem de forma dinâmica entre o estado de saúde e doença. Considera ainda que viver em uma ILPI é o principal fator que influencia no aparecimento das fragilidades.

A institucionalização está associada à imobilidade, à presença de doenças crônicas causadoras de incapacidades, a alguma incapacidade para desenvolver uma atividade diária, ao convívio com situações de violência doméstica, a ter mais de 75 anos, além de outros fatores que podem estar presentes em populações locais, caracterizando-as como frágeis ${ }^{(8-9)}$.

Seja qual for o motivo que leve à institucionalização dos idosos, alguns estudos têm relacionado essa opção de moradia como um local de segregação geracional, que produz sensações e sentimentos de isolamento, perdas, inatividade física e mental por problemas de saúde ou por falta de oportunidade, repercutindo na qualidade de vida desses indivíduos. Podem, inclusive, propiciar o aumento da dependência funcional, sobretudo porque a padronização da assistência, com horários previamente estabelecidos, normas e rotinas predeterminadas, com o objetivo de controlar cada vez melhor os acontecimentos nas ILPIs, favorece a perda de autonomia, do autocuidado e da participação efetiva no cotidiano coletivo ${ }^{(10-14)}$.

\section{CONSIDERAÇÕES FINAIS}

A avaliação da capacidadefuncional em idosos institucionalizados apresenta-se como um instrumento facilitador e necessário para a implementação de ações terapêuticas e avaliativas. Isso desde que se desconsiderem as generalizações conceituais sobre os valores bioéticos de autonomia, cuja linguagem do direito sobrepõe as limitações funcionais das pessoas idosas às regulamentações das instituições, que representam socialmente a exclusão da utilidade dos seres independentes e capazes.

A enfermagem tem se dedicado a construir teorias interativas, participativas e autônomas voltadas para o cuidado humano, com o intuito de possibilitar cada vez mais informações para o autocuidado. Nesse sentido, a teoria do déficit do autocuidado propõe-se a realizar os cuidados com o corpo e a mente daqueles indivíduos que não conseguem fazê-lo, através de práticas sistematizadas do cuidado, tanto de forma individual quanto coletiva. Mas, sobretudo, sugere práticas humanizadoras, compreensivas e responsáveis pela manutenção do bem-estar físico, mental, biológico, espiritual, ambiental e psicológico, por meio de um plano de cuidados terapêuticos acolhedores, que permitam ao idoso conviver da melhor maneira possível dentro de suas limitações e possibilidades.

\section{Referências}

1. World Health Organization. Envelhecimento ativo: uma política de saúde. Brasilia: Organização Pan-Americana de Saúde; 2005.

2. Gonçalves LHT. O idoso institucionalizado: avaliação da capacidade funcional e aptidão física. Cad Saúde Pública. 2010;26(9):1738-46.

3. Macedo C, Gazzola JM, Najas M. Síndrome da fragilidade no idoso: importância da fisioterapia. Arq Bras Ciênc Saúde. 2008;33(3):177-84.

4. Agich GJ. Dependência e autonomia na velhice: um modelo ético para o cuidado de longo prazo. São Paulo: Loyola, Centro Universitário São Camilo; 2008. p. 27-45.

5. Nunes VMA, Menezes RMP, Alchieri JC. Avaliação da qualidade de vida em idosos institucionalizados no município de Natal, Estado do Rio Grande do Norte. Acta Sci., Health Sci. 2009;32(2):119-26.

6. Murakami L, Scattolin F. Avaliação da independência funcional e da qualidade de vida de idosos institucionalizados. Rev Med Hered. 2010;21(1):18-26.

7. Ministério da Saúde (BR). Secretaria de Atenção à Saúde. Departamento de Atenção Básica. Envelhecimento e saúde da pessoa idosa. Brasilia: Ministério da Saúde; 2006. Cadernos de Atençăo Básica - no 19. Série A. Normas e Manuais Técnicos.
8. Duarte YAO. Envelhecimento, funcionalidade e arranjos domiciliares na América Latina e Caribe [tese]. São Paulo: Escola de Enfermagem da USP; 2005.

9. Ricci NA, Kubota MT, Cordeiro RC. Concordância de observaçōes sobre a capacidade funcional de idosos em assistência domiciliar. Rev Saúde Pública. 2005;39(4):655-62.

10. Lenart MH. O idoso institucionalizado e a cultura de cuidados profissionais.

Cogitare Enferm. 2006;11(2):117-23.

11. Barbosa ET, Werba GC. Arteterapia e idosos institucionalizados: uma

experiência no tempo. Conversas Interdiscip. 2010;1 (1):1-14.

12. Canonici AP. Análise comparativa da capacidade funcional de idosos

esquizofrênicos institucionalizados. Rev Movimenta. 2008;1(1):11-4.

13. Jesus IS. Cuidado sistematizado a idosos com afecção demencial residentes em instituição de longa permanência. Rev Gaúcha Enferm. 2010;31(2):285-92. 14. Araújo MOPH, Ceolim MF. Avaliação do grau de dependência de idosos residentes em instituiçōes de longa permanência. Rev Esc Enferm USP. 2007;41(3):378-85. 